\title{
3D models related to the publication: The hidden teeth of sloths: evolutionary vestiges and the development of a simplified dentition.
}

\author{
Hautier Lionel ${ }^{1 *}$, Gomes Rodrigues Helder², Billet Guillaume ${ }^{3}$, Asher Robert J. ${ }^{4}$ \\ ${ }^{1}$ Institut des Sciences de l'Evolution de Montpellier, Université de Montpellier, CNRS, IRD, Cc 064; place Eugène Bataillon, 34095 Montpellier \\ Cedex 5, France. \\ ${ }^{2}$ Sorbonne Universités, CR2P, UMR CNRS 7207, Univ Paris 06, Muséum national d'Histoire naturelle, 8 rue Buffon, 75005 Paris, France. \\ ${ }^{3}$ CR2P - UMR 7207 CNRS, MNHN, Univ Paris 06, Paris, France \\ ${ }^{4}$ Department of Zoology, University of Cambridge, Downing St., Cambridge CB2 3EJ, UK. \\ *Corresponding author: lionel.hautier@univ-montp2.fr
}

\begin{abstract}
This contribution contains the 3D models described and figured in the following publication: Hautier L., Gomes Rodrigues H., Billet G., Asher R.J., 2016. The hidden teeth of sloths: evolutionary vestiges and the development of a simplified dentition. Scientific Reports. doi: 10.1038/srep27763
\end{abstract}

Keywords: homology, ontogeny, sloths, vestigial teeth

Submitted:2016-04-28, published online:2016-06-14. doi: 10.18563/m3.2.2.e1

\section{Model IDs \\ M3\#109_ZMB 41122 \\ M3\#110_ZMB 33812 \\ M3\#111_MNHN-ZM-MO- \\ 1995-326A \\ M3\#112_MNHN-ZM-MO-_Bradypus variegatus \\ 1995-326B \\ M3\#113_MNHN-ZM-MO- \\ 1902-325 \\ M3\#114_MNHN-ZM-MO- \\ 1995-327 \\ M3\#115_MNHN-ZM-MO \\ $1882-625$ \\ Table 1. List of associated models. All models stand as labelled three-dimensional reconstructions of the teeth, mandibles, maxillary and premaxillary bones.}

\section{INTRODUCTION}

This contribution contains a selection of the 3D models (see Table 1) described and figured in the following publication: Hautier, L., Gomes Rodrigues, H., Billet, G., Asher, RJ. 2016. The hidden teeth of sloths: evolutionary vestiges and the development of a simplified dentition. In this study, we present new data on xenarthran prenatal dental ontogeny and identify some developmental criteria with which to recognize homologies with other mammalian teeth. Our developmental data for extant sloths directly supports the claim that their lower caniniform teeth are not homologous to canines of other mam- mals and that upper caniniforms are not homologous between the two-toed and the three-toed sloths (Hautier et al., 2016)

\section{METHODS}

AVIZO 7.1 (Visualization Sciences Group) software was used for visualization, segmentation and $3 \mathrm{D}$ rendering. The teeth, dentary, maxillary, and premaxillary bones were extracted within a "labelfield" module of AVIZO, using the segmentation threshold selection tool. The 3D models are provided in .ply format, and as such can be opened with a wide range of freeware. Additional flag and position files specific to ISEMeshTools (Lebrun, 2014) are provided in order to visualize the 3D labelled models in standard orientation.

\section{ACKNOWLEDGEMENTS}

We are grateful to M. Herbin, C. Bens, G. Véron, A. Verguin, F. Renoult, C. Denys and J. Cuisin (Museum National d'Histoire Naturelle, Paris), Peter Giere and Frieder Mayer (Museum für Naturkunde, Berlin), and their colleagues for access to comparative material. N. Karjilov (Helmholtz Zentrum Berlin), M. García-Sánz (AST-RX platform, Muséum national d'Histoire naturelle, Paris, France), F. Landru, C. Morlier, G. Guillemain and all the staff from Viscom SARL (St Ouen l'Aumône, France) provided generous help and advice with $\mathrm{CT}$ acquisition. This work has benefited from an "Investissements d'Avenir" grant managed by Agence Nationale de la Recherche, France (CEBA, ref. ANR-10-LABX-25-01). 


\section{BIBLIOGRAPHY}

Hautier, L., Gomes Rodrigues, H., Billet, G., Asher, RJ. 2016.

The hidden teeth of sloths: evolutionary vestiges and the development of a simplified dentition. Scientific Reports. doi: 10.1038/srep27763

Lebrun, R., 2014. ISE-MeshTools, a 3D interactive fossil reconstruction freeware. 12th Annual Meeting of EAVP, Torino, Italy 